\title{
A Mathematical Approach To Demand Estimation In Multi-Segment Oligopoly Markets - With An Application To The Automobile Market
}

Robert P. Culp, (E-mail: DrCulp@psu.edu), Penn State University Lehigh Valley

\begin{abstract}
The purpose of this paper is to develop a purely mathematical approach to determining consumer demand. The model developed allows the researcher to derive demand in an oligopoly market from observed firm output and market prices using only assumptions about each firm, modest restrictions on consumer behavior, and limitations on market structure. The advantage of this revealed demand approach is that it does not require the specification of the consumer's utility function or any firm's production function. In addition, this mathematical approach allows for the estimation of own price and cross price elasticities of demand without statistical regression.
\end{abstract}

The mathematical model developed is applied to the automobile industry assuming a market characterized by Cournot-Nash behavior and divided into five homogenous vehicle segments. A global optimization program is used to mathematically determine the range of values the coefficients of demand must take in each segment to satisfy market equilibrium. These coefficients can be used to estimate own and cross price elasticities of demand and construct demand equations.

The elasticity estimates generated by the mathematical model of the automobile industry are compared to other estimates of elasticity found by statistical estimation. It is shown that the mathematical model generates results that are consistent with the statistical methods of the automobile market used by other researchers.

\section{Introduction}

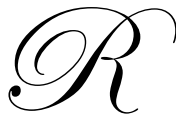

ecent methods of estimating demand in the automobile market have focused on treating vehicle purchases as a bundle of characteristics for which consumers have preferences. It assumes that each consumer chooses the vehicle that contains the bundle of characteristics that maximizes utility. Market demand is obtained from the aggregation of consumers' choices. In order to aggregate these results, the functional form of the utility function must be specified. The functional form of the utility function is selected so individual preferences may be aggregated into an overall demand function in each vehicle segment. This method allows the researcher to estimate the value consumers place on different vehicle characteristics.

Berry, Levinsohn, and Pakes (1995) use this approach. In their paper, they establish a general approach to determining market demand coefficients by using a set of first order conditions that must be satisfied for equilibrium to occur in the Cournot-Nash framework. They then solve these first order conditions in terms of the coefficients of vehicle characteristics and prices. This approach is referred to in this paper as a Revealed Demand System (RDS) because it assumes firms behave in a certain manner and from this assumption the coefficients of demand are revealed. 
Berry, et al. apply their general approach in the following manner. They first assume a utility function for each consumer of the same particular functional form, for example Cobb-Douglas, so that these individual consumer preferences may be aggregated into a market demand. Their utility function depends on certain vehicle characteristics: air conditioning, miles per dollar, size, and horsepower to weight. Before estimation, the utility functions are aggregated to generate a market demand function. Then a linear cost function with respect to those characteristics is assumed and combined with the market demand function to find the Cournot-Nash first order conditions for equilibrium in terms of vehicle characteristics only. These first order conditions yield a system of equations in terms of vehicle characteristics, quantity produced by each firm, and market prices. It is this system of equations that they "take to the data" for logit regression estimation of the unknown coefficients of vehicle characteristics.

Goldberg (1995) and Arguea and Hsiao (1993) each use Berry, Levinsohn and Pakes' approach. Goldberg extends the model by using a nested logit formulation rather than simple logit estimation. This allows for more reasonable substitution patterns, but again it specifies a utility function.

Arguea and Hsiao add the condition that certain vehicle characteristics are subject to competitive arbitrage. Fershtman, et al. (1999) extend the model. Instead of solving for marginal cost and then regressing the results, he derives input demand functions and solves them in terms of demand characteristics only. He then proceeds in the Berry, Levinsohn, and Pakes framework to find coefficients on vehicle characteristics.

A limitation of these approaches is that specifying the functional form of the utility function limits the nature of consumer utility and generates specific patterns of substitution that may not be consistent with consumer behavior.

\section{Approach Used in this Paper}

This paper uses a different approach. Like Berry, Levinsohn, and Pakes (BLP), firms will be assumed to follow the Cournot-Nash assumptions and each firm's first order condition will be used to reveal consumer demand, however, that is where the similarities end. Instead of restricting the consumer's utility function, restrictions are placed on market structure. In particular, vehicles within each segment are considered homogenous. With this restriction and limitations on vehicle production cost, each firm's first order conditions are used to determine what price elasticities must have been to explain the observed pricing and output decisions of each firm.

The assumption of homogenous segments may seem to be strong, but it is not unreasonable. If producers are responsive to consumer desires and consumers value a particular feature, producers will want to provide that feature especially if other producers in the same segment are offering that feature. In this way, vehicles in the same class will likely contain a common set of characteristics. In fact, this view is substantiated by the work of Fairen (1996). This research found vehicle characteristics did tend to converge toward a common set of features. Therefore, the assumption that vehicle characteristics are the same within a segment is reasonable.

Because this approach assumes homogenous segments, the first order conditions do not include vehicle characteristics. Each firm produces vehicles within a segment with a common set of characteristics and therefore the characteristics of the vehicle are not a choice variable for producers. With homogenous vehicle characteristics within each segment, each firm's only decision is how many units to produce in each segment given how production in each segment will affect their vehicle sales in other segments and how their pricing will cause competitors to react. This latter factor can be ignored if one assumes that firms fail to consider how the other firms will react. That is, if one assumes Cournot-Nash behavior, the only decision relevant to each firm is how its increased production will influence sales in each segment.

The assumption of homogenous segments greatly simplifies the first order conditions, but it also results in an inability to determine how much consumers value each feature. Without vehicle characteristics in the first order conditions, there are no coefficients to establish how much consumers value each characteristic individually. However, without differing vehicle characteristics, this approach does not require the including vehicle 
characteristics in each firm's first order conditions-reducing the complexity of the system of first order conditions. In addition, because producers have the same common set of features for each vehicle, the production costs for each vehicle can be represented by a single cost of production that includes all production costs including the cost of selling the vehicles through dealerships.

This method is analogous to the revealed preference method used in utility theory. Just as consumer behavior, given known constraints, reveals the consumer's underlying utility function; a firm's behavior, given certain assumptions, can reveal important aspects of consumer demand.

\section{A Revealed Demand Approach to Estimating Demand Systems}

The revealed demand approach determines the elasticites of demand at equilibrium by assuming firms act in a certain manner. In this case, firms are assumed profit maximizers in the Cournot-Nash framework. Accordingly, each firm seeks to maximize profits assuming changes in their output will not change the output decisions of competing firms. However, they do take into account how changes in their own output will impact market price. Since one of the manufacturing assumptions made above is that the marginal cost of producing each good is independent of the production of the other goods, each firm's objective function is:

Max profits: $\Pi=\mathrm{P} Q-\mathrm{TC}$ where $\mathrm{P}$ is the vector of prices in each automotive segment, $\mathrm{Q}$ is the vector of quantities produced by each firm in each segment and TC is the total cost of all production in each segment.

Therefore, assuming the cost of production in one market segment is independent of the quantity produced in any other market segment, each $\mathrm{i}^{\text {th }}$ firm's first order conditions (FOC) are ${ }^{1}$ :

$$
\begin{aligned}
& \frac{\partial \Pi_{i}}{\partial x_{i}}=P_{x}+\frac{\partial P_{x}}{\partial x_{i}} X_{i}+\frac{\partial P_{y}}{\partial x_{i}} Y_{i}+\ldots \frac{\partial P_{z}}{\partial x_{i}} Z_{i}-M C_{x i}=0 \\
& \frac{\partial \Pi_{i}}{\partial y_{i}}=P_{y}+\frac{\partial P_{x}}{\partial y_{i}} X_{i}+\frac{\partial P_{y}}{\partial y_{i}} Y_{i}+\ldots \frac{\partial P_{z}}{\partial y_{i}} Z_{i}-M C_{y i}=0 \\
& \cdot \\
& \frac{\partial \prod_{i}}{\partial z_{i}}=P_{z}+\frac{\partial P_{x}}{\partial z_{i}} X_{i}+\frac{\partial P_{y}}{\partial z_{i}} Y_{i}+\ldots . \frac{\partial P_{z}}{\partial z_{i}} Z-M C_{z i}=0
\end{aligned}
$$

FOCs repeated for each of $\mathrm{N}$ firms

Where $\{\mathrm{x}, \mathrm{y}, \ldots, \mathrm{z}\}$ represent the different products each firm can make. $\mathrm{P}_{\mathrm{x}}, \mathrm{P}_{\mathrm{y}}, \mathrm{P}_{\mathrm{z}}$ are the market prices at equilibrium, and $\mathrm{X}_{\mathrm{i}}, \mathrm{Y}_{\mathrm{i}}, \mathrm{Z}_{\mathrm{i}}$ are the quantities produced by the $\mathrm{i}^{\text {th }}$ firm at equilibrium, and $\mathrm{MC}$ is the marginal cost of the last unit produced.

For a Cournot-Nash equilibrium to exist each of the FOC listed in equation set 1 must simultaneously hold.

After substituting for the known variables of market price in each market segment and quantity sold in each market segment by each firm, the above system of equations can be solved for the coefficients of demand in terms of each firm's marginal costs and the coefficients of demand.

${ }^{1}$ Each firm's actual FOC is $\frac{\partial \Pi_{1}}{\partial Q_{1}}=\sum \frac{\partial P}{\partial Q_{1}} \frac{\partial Q_{1}}{\partial Q_{i}}+\frac{\partial P}{\partial Q_{1}} \frac{\partial Q_{1}}{\partial Q_{1}}+P-\frac{\partial T C_{1}}{\partial Q_{1}}=0$ but since Cournot-Nash assumes $\frac{\partial Q_{1}}{\partial Q_{i}}=0$, this FOC simplifies to
the equations given above. 
Since the effect of an increase in output by any firm has the same effect on price as an increase in industry output in the Cournot-Nash equilibrium, this means that for all firms i $\rightarrow \mathrm{k}$ :

$\frac{\partial P_{x}}{\partial x_{T}}=\frac{\partial P_{x}}{\partial x_{i}}=\frac{\partial P_{x}}{\partial x_{j}}=\ldots=\frac{\partial P_{x}}{\partial x_{k}}$

where $\mathrm{x}_{\mathrm{T}}$ is industry output.

Therefore, if the marginal cost of the last unit sold by each firm were known, the above system of equations would be expressed solely in terms of the coefficients of demand.

There are two difficulties with this approach. First, some variables may not be precisely known. Second, the number of unknown variables may be greater than the number of equations resulting in equations that are solved not only in terms of known variables but also in terms of unknown variables. Not explicitly solving the system of equations, but rather determining a range of values that satisfy the system of equations, however, can address both of these problems. To do so, certain assumptions are made about consumer behavior and the range of values that certain variables must take. Therefore, the coefficients of demand in each market segment can be found within a certain range. From these coefficients, elasticities of demand can be calculated.

\section{Potential Problems with Incorrectly Specifying the Market Structure}

Since this model uses firm behavior and market structure to determine demand, misspecification of the market structure can lead to incorrect results. In particular, there are two misspecifications to be examined. The first is if the homogenous assumption of the model does not hold. In particular, if the model incorrectly combines unrelated vehicle segments, the results could be incorrect. The second is the improper combining of unrelated firms. In this research, smaller firms with separate ownership are assumed to act as a one unified firm, this could result in underestimating the amount of competition in the market. This could result in attributing the price that prevails in the market to consumer preferences rather than a higher level of competition. Since either of these model misspecifications could affect the results, the consequences of these misspecifications should be examined.

First, suppose in specifying the market structure that unrelated segments are lumped together as one unit. Accordingly, the average price used in the revealed demand system (RDS) would really be the average of the price between the two markets and total output would be the combination of the two markets. As a result, the RDS will find the elasticities that explain this average pricing and output behavior. Therefore, the RDS will estimate a weighted average of the two markets and the RDS' elasticity estimates will not reflect the true elasticity of the individual markets. However, since the elasticity estimate is a weighted average of the two markets, the results are influenced as any average would. In other words, the RDS estimate of elasticities will be closer to the market with more observations. However, if the elasticities of the individual segments are close, then the elasticities found by the RDS will be close.

The impact of the second type of misspecification, incorrectly combining firms to act as one firm, is less severe, assuming the remaining firms are correctly specified. In particular, if two competing firms that make independent output decisions are incorrectly assumed to behave as one single decision making body, the RDS will incorrectly attribute the combined firm's high level of output to a lower cost of production rather than competition.

The possibility of incorrect combination is not a severe problem because regardless of the number of firms in the market, the correctly specified individual firm's first order condition equations will stay the same. Therefore, the correctly specified firms' first order condition equations still must be satisfied and can only be satisfied by a limited range of elasticities and costs. This means the estimates of elasticities at market equilibrium by the RDS must still explain the correctly specified firms' output decisions and therefore be close to the true values of elasticities. 
Thus far, the properties of the demand system were specified and previous methods of demand estimation were examined. Next, this approach is applied to the automobile market to estimate vehicle elasticities.

\section{Applying the RDS to the Automobile Industry}

To obtain estimates of the coefficients on demand requires establishing the market structure and then obtaining the relevant data.

\section{Market Structure}

Since the top three automakers, General Motors, Ford, and Chrysler held around 75 percent of the U.S. market during the 1989-1996 time frame of this study, and none of the remaining firms obtained much more than 10 percent market share, the remaining firms were combined into one firm called "Alternative producers." The U.S. auto market consists of new vehicles sold in the U.S., regardless of manufacturing location.

Therefore, the model of the automobile industry used in this paper consists of firms grouped into the four following divisions:

1. $\quad$ Ford

2. Chrysler

3. General Motors

4. Alternative producers

Vehicles were assigned into homogenous segments partially on use, but also on manufacturing facilities. The view of homogenous segments is supported by manufacturing reports from Harbour, an industry trade publication, which show that a variety of models share the same manufacturing facilities for many of their key components. For example, Ford's Lima, Peru production facility makes an engine that is used for Ranger pickups, Aerostar/Windstar vans, and Sable/Taurus sedans. In addition, Ford also uses the same transmissions in a wide assortment of vehicles from their large Crown Victoria sedans, Econoline vans, F-series pickups, Expedition and Explorer SUVs, to Mustang sports cars.

As Friedlaender et al. (1983) observed "Not only are the same dies used to produce parts for a wide range of different models and makes, but parts and major components such as engines are often interchangeable as well. Therefore, from the point of view of production it seems reasonable to define output in terms of broad product lines (e.g. luxury, full size, compact, subcompact, etc.).Each of which has a range of generic attributes (e.g. wheelbase, weight, engine displacement, etc.)."

Furthermore, the assumption of homogenous segments is also supported by Fairen (1996). In his study, Fairen found that vehicle characteristics tend to converge toward a common set of features. Therefore, the assumption that vehicle characteristics are homogenous within each segment is reasonable.

Vehicles are assigned to segments as determined by Ward's Automotive. Ward's Automotive is an industry observer that collects information on various aspects of the automobile industry. The segments are generally organized according to vehicle characteristics, and coincidentally, emission rates. The following categories divide the automobile market into five homogenous segments:

1. Small Sedan

2. Large Sedan

3. SUVs

4. Pickups and Vans

5. Luxury Vehicles 
The number of firms and products are limited for two reasons. First, not every small firm produces vehicles in every segment. Second, for computational reasons it was necessary to limit the number of firms and products because the time required for computation increases dramatically as the number of products and number of firms increase.

\section{The Data}

The next step in applying the RDS is obtaining the relevant data. The data required is vehicle price in each segment, vehicle sales by each producer in each segment, and the marginal cost of the last vehicle sold by each producer in each segment.

\section{Vehicle Price Data}

Information from the Consumer Expenditure Survey was used to obtain estimates of vehicle price in each segment as paid by consumers. The Consumer Expenditure Survey (CES) conducted by the Bureau of Labor Statistics contains information about all individual household purchases, demographic information and household income. The CES contains information on household vehicle purchases by make, model and year, and reports the price paid for each vehicle. For this paper, vehicle price in each segment was estimated from the average price paid by households for vehicles in the corresponding segment.

\section{Vehicle Sales Data and Segment Categorization}

Vehicle sales and segmentation data were obtained from Ward's Automotive. Ward's Automotive reports automobile sales in nine segments: commercial, cross utility, large sedan, mid-size sedan, small car, pickup, sport utility, van, and luxury vehicle. Commercial vehicles were not included in this paper since their demand is likely to be significantly different from consumer demand. Cross utility vehicles were combined into SUV sales since these vehicles are very similar and this category was not created until 1996. Mid-size sedans were combined into large sedan sales because the price of vehicles in the large category had prices comparable to, and many cases cheaper, than mid-size sedans. Vans and pickups were combined into one segment for two reasons. First, these vehicles are similarly priced and are interchangeable to many consumers. Second, vans and pickups use many of the same components and production facilities so their cost of production is similar.

The model used in this paper assumes that vehicles within each segment are homogenous hence the collection of average price paid in each segment. This assumption is also consistent with research done by Bajic in which he found strong substitutability between automobile characteristics (Bajic 1993).

\section{Marginal Cost Data}

The next piece of data collected was marginal cost, but exact information about the marginal cost of the last unit for each automobile producer was not readily available. Each corporation closely holds this information, for obvious competitive reasons. Therefore, ranges of reasonable costs were assumed that were consistent with information found in the Harbour Yearbook, an industry trade publication, and information provided by the Office of Automotive Transportation. The Office of Automotive Transportation provided information regarding the minimum gross profit per vehicle per segment and the minimum marginal cost of each vehicle.

The minimum marginal cost of vehicle production in each category was reported to be greater than $\$ 8000$ in each segment. More specific information was not available. This marginal cost estimate includes on-site manufacturing cost, delivery, variable marketing agreements, and dealer compensation.

To summarize, gross profit and marginal cost data were reported to be the following ${ }^{2}$ :

1. Gross profit of at least $\$ 1000$ on small vehicles

\footnotetext{
${ }^{2}$ The gross profit figures were obtained from internal domestic producer documents.
} 
2. Gross profit of at least $\$ 3500$ on mid to large vehicles

3. Gross profit of at least $\$ 5000$ on all other vehicles

4. Marginal cost of at least $\$ 8000$ on all vehicles

\section{Application of Gross Profit Data}

The gross profit information is very important because it allows for the calculation of a range of values that contain the true marginal cost; if marginal cost equals average variable cost, then gross profits can be used to estimate marginal cost. This is illustrated below:

Since gross profit per vehicle $=$ price - average variable cost , and

1. If marginal cost $=$ average variable cost, then

2. $\quad$ gross profit per vehicle $=$ price - marginal cost.

Therefore, given gross profit per vehicle and the assumption that $\mathrm{AVC}=\mathrm{MC}$, if price and gross profit per vehicle are known, then marginal cost would be known.

However, gross profit is not precisely known. Instead, it is known that gross profit is greater than the amounts mentioned earlier, therefore, it can only be said that marginal cost is less than a certain amount:

$\mathrm{MC}<$ price - gross profit per vehicle

\section{Production Characteristics of the Industry}

It is not assumed that every manufacturer's marginal cost equals average variable cost. In fact, it is only assumed that one manufacturer's marginal cost equals average variable cost. That manufacturer is General Motors (G.M.) because of the nature of G.M.'s production capacity compared to other automakers as explained next.

The assumption that G.M.'s marginal cost is equal to its average variable cost is based in part on the fact that the automobile industry is very capital intensive. When a firm is highly capital-intensive productivity remains high over large ranges of output since machines can perform repetitive tasks for long periods without losing efficiency. Therefore, if a firm in this industry is not working too close to full capacity, where machinery would become a constraining factor, the marginal cost of the last unit should be very close to the marginal cost on the first unit. Furthermore, since the scale of the operation is so large, any setup costs are distributed over enough units that the setup costs have a negligible effect on average variable cost. This means that the marginal cost of the last unit would be very close to the overall average variable cost.

\section{Distinguishing Production Characteristics of G.M.}

Average variable cost is assumed to equal marginal cost for G.M. based on their excess capacity. The need for regular down-time maintenance of their machinery causes most auto manufacturers to operate their production facilities for only two shifts, although Chrysler routinely operates three shifts (Harbour Yearbook). If a firm is operating at the maximum of the two-shift capacity, the marginal cost to produce the next vehicle would be very high because a whole additional shift would be needed to produce the additional unit. Further, a firm that decides to operate three shifts has increased maintenance costs due to the difficulty of performing maintenance while a shift is working or trying to perform maintenance during shorter time intervals (Harbour Yearbook). These factors result in the marginal cost of additional units requiring a third shift to be much higher than average variable cost.

G.M. production levels seldom require a third shift (Habour Reports), and therefore it is unlikely that G.M.'s marginal cost varies significantly from its average variable cost. This may not be true for other manufacturers who operate close to 2-shift capacity and may need to add a third shift from time to time to increase vehicle production. Therefore, constraints can reasonably be placed on G.M.'s gross profits but not on the other manufacturers. 


\section{Additional Assumptions Needed to Apply the Model}

Since exact values for the marginal cost of each manufacturer are not known, the entire RDS model can not be solved for the exact partials (price elasticities). It is possible to construct a limited range of possible elasticities given some assumptions about demand and the cost advantages of certain producers. In particular, the following additional assumptions will be made:

1. Coefficients on demand must be substitutes in consumption

2. $\quad$ Cross price effects are symmetric

3. Own price effects must be greater than cross price effects

4. Restrictions derived from comparing marginal costs between segments and between firms given their respective market shares (as explained below)

The first assumption implies that all coefficients of demand are less than zero, demand is downward sloping, and all cars are substitutes of some degree for each other. The second assumption that cross price coefficients are symmetric guarantees a maximum solution rather than a minimum. Further it stipulates that for substitutes an increase in quantity in one segment will impact price in the other segment the same as an increase in the quantity in the other will impact the price of the first good. This is true as long as there is not an income effect from the purchase of automobiles. This assumption is reasonable given that a consumer is unlikely to buy more than one vehicle because of a slight decline in price. The third assumption that own price effects are greater than cross price effects assures that vehicles within the same segment are closer substitutes than vehicles in other segments.

The fourth assumption includes the following restrictions:

1. Following Cournot-Nash behavioral assumptions, the firm with the greater production will have a lower marginal cost than a lower producing competitor.

2. The marginal cost of the last vehicle sold is less than the price of the vehicle.

3. Cross price coefficients have less impact on price than own price coefficients.

To be consistent with what is known about vehicle production costs and gross profits between different vehicle segments, the following restrictions were also imposed:

1. The marginal cost for G.M. to make a large sedan is less than the marginal cost of G.M. to make a SUV or luxury vehicle.

2. The marginal cost for G.M. to make a pickup is less than the marginal cost for G.M. to make a luxury vehicle.

3. The markup for G.M. on small vehicles is less than the markup for G.M. on pickups or luxury vehicles.

4. The markup for G.M. on large sedans is less than the markup on SUVs.

5. The markup for G.M. on pickups is less than the markup on luxury vehicles.

In addition, all coefficients are assumed to be less than -0.00000001. In other words, if vehicle production in any segment during one quarter increased by 10 million units then all vehicle prices would be impacted by at least $\$ 1$. Given that total vehicle production in one quarter does not exceed 10 million units, this restriction seems reasonable. Finally, all coefficients are assumed to be greater than -1 which means that all coefficients are between 1 and -0.00000001 . The restriction that all coefficients are greater than -1 is needed to limit the search area for the global optimization program; it is not binding and has no impact on the model.

\section{First Order Conditions}

Applying the first order conditions found in the prior chapter to the defined four firms, five product market, generates the following 20 first order conditions for profit maximization and consistency with the Cournot-Nash equilibrium: 


$$
\begin{aligned}
& p_{1}^{i}+\frac{\partial p_{1}}{\partial q_{1}} \cdot q_{1}^{i}+\frac{\partial p_{2}}{\partial q_{1}} \cdot q_{2}^{i}+\frac{\partial p_{3}}{\partial q_{1}} \cdot q_{3}^{i}+\frac{\partial p_{4}}{\partial q_{1}} \cdot q_{4}^{i}+\frac{\partial p_{5}}{\partial q_{1}} \cdot q_{5}^{i}-M C_{1}^{i}=0 \\
& p_{2}^{i}+\frac{\partial p_{1}}{\partial q_{2}} \cdot q_{1}^{i}+\frac{\partial p_{2}}{\partial q_{2}} \cdot q_{2}^{i}+\frac{\partial p_{3}}{\partial q_{2}} \cdot q_{3}^{i}+\frac{\partial p_{4}}{\partial q_{2}} \cdot q_{4}^{i}+\frac{\partial p_{5}}{\partial q_{2}} \cdot q_{5}^{i}-M C_{2}^{i}=0 \\
& p_{3}^{i}+\frac{\partial p_{1}}{\partial q_{3}} \cdot q_{1}^{i}+\frac{\partial p_{2}}{\partial q_{3}} \cdot q_{2}^{i}+\frac{\partial p_{3}}{\partial q_{3}} \cdot q_{3}^{i}+\frac{\partial p_{4}}{\partial q_{3}} \cdot q_{4}^{i}+\frac{\partial p_{5}}{\partial q_{3}} \cdot q_{5}^{i}-M C_{3}^{i}=0 \\
& p_{4}^{i}+\frac{\partial p_{1}}{\partial q_{4}} \cdot q_{1}^{i}+\frac{\partial p_{2}}{\partial q_{4}} \cdot q_{2}^{i}+\frac{\partial p_{3}}{\partial q_{4}} \cdot q_{3}^{i}+\frac{\partial p_{4}}{\partial q_{4}} \cdot q_{4}^{i}+\frac{\partial p_{5}}{\partial q_{4}} \cdot q_{5}^{i}-M C_{4}^{i}=0 \\
& p_{5}^{i}+\frac{\partial p_{1}}{\partial q_{5}} \cdot q_{1}^{i}+\frac{\partial p_{2}}{\partial q_{5}} \cdot q_{2}^{i}+\frac{\partial p_{3}}{\partial q_{5}} \cdot q_{3}^{i}+\frac{\partial p_{4}}{\partial q_{5}} \cdot q_{4}^{i}+\frac{\partial p_{5}}{\partial q_{5}} \cdot q_{5}^{i}-M C_{5}^{i}=0
\end{aligned}
$$

For each $\mathrm{i}^{\text {th }}$ firm, where the partials are the own and cross price coefficients, and the $\mathrm{q}^{\mathrm{i}}$ variables represent the number of vehicles sold by the $\mathrm{i}^{\text {th }}$ firm in market segments 1 through 5 . Where $\mathrm{p}$ represents the price in each segment, and the $M C^{\mathrm{i}}$ variables represent the marginal cost of the $\mathrm{i}^{\text {th }}$ producer in market segments 1 through 5.

\section{Determining Coefficient Values that Satisfy the FOCs}

Since prices and quantities sold by each firm are known, the first order system of equations can be solved for the own price and cross price coefficients of demand. The only exception is that five price coefficient variables can not be solved since the number of unknown variables is greater than the number of equations. Therefore, the optimization program will consider the price coefficients as exogenous. The remaining coefficients of demand can be expressed in terms of known variables and the exogenous variables. In particular, each coefficient of demand is solved in terms of the marginal cost of production for each firm in each segment, prices, and the exogenous price coefficients. The first order equations for each quarter were solved by Mathematica.

Summarizing, if prices, quantity sold by each firm, the marginal cost of the last unit sold by each firm, and the exogenous price coefficients were known, these coefficient equations would reveal the value of the remaining coefficients of demand.

\section{Revealed Demand}

While the exogenous cross price coefficient variables are not known, and marginal cost is only known within certain values, the exogenous coefficients of demand are still bound by the first order conditions and the assumptions of the model. This effectively limits the range of values these variables can take, and thus, reveals the coefficients of demand even for these exogenous coefficients. These coefficients can be used to calculate own and cross price elasticities.

Using the constraints and the coefficient equations established in this chapter, a range of values was calculated for each coefficient. This was done using the Frontline Systems global optimization software to find the minimum/maximum value each coefficient on demand could take while satisfying the coefficient equations and the restricting assumptions. The quarterly results of the optimization program are reported in own price elasticity form in Table 1.

Table 1: Own price Elasticities by Quarter

\begin{tabular}{|l|r|r|r|r|r|r|r|r|}
\hline Quarter & $\mathbf{1}$ & $\mathbf{2}$ & $\mathbf{3}$ & $\mathbf{4}$ & $\mathbf{5}$ & $\mathbf{6}$ & $\mathbf{7}$ & $\mathbf{8}$ \\
\hline Max small sedan & -3.62 & & -1.96 & -2.90 & -3.44 & -4.03 & -4.71 & -6.25 \\
\hline Min small sedan & -1.42 & & -1.44 & -1.83 & -1.62 & -1.43 & -1.35 & -1.36 \\
\hline
\end{tabular}




\begin{tabular}{|c|c|c|c|c|c|c|c|}
\hline Max Large sedan & -2.36 & -3.26 & -1.51 & -3.39 & -3.38 & -3.60 & -3.54 \\
\hline Min Large sedan & -0.92 & -0.96 & -0.81 & -0.83 & -0.86 & -0.82 & -0.77 \\
\hline Max SUVs & -2.65 & -2.65 & -1.93 & -1.74 & -2.12 & -1.91 & -15.27 \\
\hline Min SUVs & -0.67 & -0.76 & -0.76 & -0.65 & -0.64 & -0.62 & -0.52 \\
\hline Max Pickups/vans & -3.94 & -5.99 & -1.32 & -5.62 & -5.92 & -5.68 & -5.61 \\
\hline Min Pickups/vans & -0.95 & -1.14 & -1.06 & -1.22 & -0.91 & -0.84 & -0.82 \\
\hline Max Luxury & -14.03 & -20.78 & -3.26 & -21.32 & -22.81 & -20.98 & -15.92 \\
\hline Min Luxury & -0.56 & -0.62 & -0.47 & -0.53 & -0.49 & -0.53 & -0.54 \\
\hline
\end{tabular}

\begin{tabular}{|l|r|r|r|r|r|r|r|r|}
\hline Quarter & $\mathbf{9}$ & $\mathbf{1 0}$ & $\mathbf{1 1}$ & $\mathbf{1 2}$ & $\mathbf{1 3}$ & $\mathbf{1 4}$ & $\mathbf{1 5}$ & $\mathbf{1 6}$ \\
\hline Max small sedan & -1.75 & -3.25 & -8.00 & -2.97 & -8.92 & -2.02 & -4.94 & -10.17 \\
\hline Min small sedan & -1.44 & -1.84 & -1.40 & -1.18 & -1.24 & -1.25 & -1.23 & -1.01 \\
\hline Max Large sedan & -1.30 & -1.44 & -4.10 & -1.65 & -1.11 & -4.01 & -3.95 & -1.68 \\
\hline Min Large sedan & -0.84 & -0.85 & -0.79 & -0.76 & -0.71 & -0.74 & -0.65 & -0.58 \\
\hline Max SUVs & -2.19 & -1.12 & -14.63 & -7.54 & -2.43 & -3.45 & -1.93 & -3.22 \\
\hline Min SUVs & -1.06 & -0.55 & -0.49 & -0.51 & -0.55 & -0.52 & -0.54 & -0.47 \\
\hline Max Pickups/vans & -5.39 & -4.48 & -4.69 & -4.89 & -6.23 & -6.92 & -4.89 & -6.38 \\
\hline Min Pickups/vans & -1.07 & -0.95 & -0.79 & -0.83 & -0.74 & -0.72 & -0.86 & -0.73 \\
\hline Max Luxury & -17.65 & -21.28 & -10.99 & -18.80 & -23.49 & -22.12 & -14.55 & -12.80 \\
\hline Min Luxury & -0.59 & -0.53 & -0.62 & -0.65 & -0.49 & -0.51 & -0.56 & -0.49 \\
\hline
\end{tabular}

\begin{tabular}{|l|r|r|r|r|r|r|r|r|}
\hline Quarter & $\mathbf{1 7}$ & $\mathbf{1 8}$ & $\mathbf{1 9}$ & $\mathbf{2 0}$ & $\mathbf{2 1}$ & $\mathbf{2 2}$ & $\mathbf{2 3}$ & $\mathbf{2 4}$ \\
\hline Max small sedan & -1.81 & -4.10 & -4.63 & -8.13 & -1.90 & -7.37 & -3.04 & -13.99 \\
\hline Min small sedan & -0.96 & -0.93 & -0.95 & -0.80 & -0.82 & -2.17 & -0.99 & -0.89 \\
\hline Max Large sedan & -3.83 & -1.53 & -2.93 & -2.94 & -3.52 & -3.94 & -1.00 & -4.07 \\
\hline Min Large sedan & -0.64 & -0.64 & -0.61 & -0.60 & -0.59 & -0.56 & -0.56 & -0.59 \\
\hline Max SUVs & -2.32 & -3.22 & -1.39 & -1.74 & -1.35 & -1.53 & -1.62 & -2.93 \\
\hline Min SUVs & -0.44 & -0.48 & -0.66 & -0.47 & -0.47 & -0.47 & -0.45 & -0.55 \\
\hline Max Pickups/vans & -6.01 & -6.82 & -1.38 & -1.61 & -6.62 & -6.75 & -5.14 & -6.66 \\
\hline Min Pickups/vans & -0.69 & -0.78 & -0.80 & -0.72 & -0.70 & -0.69 & -0.64 & -0.63 \\
\hline Max Luxury & -8.66 & -8.09 & -20.59 & -8.23 & -7.06 & -11.44 & -14.94 & -20.01 \\
\hline Min Luxury & -0.55 & -0.53 & -0.55 & -0.48 & -0.59 & -0.50 & -0.54 & -0.51 \\
\hline
\end{tabular}

\begin{tabular}{|l|r|r|r|r|r|r|r|r|}
\hline Quarter & $\mathbf{2 5}$ & $\mathbf{2 6}$ & $\mathbf{2 7}$ & $\mathbf{2 8}$ & $\mathbf{2 9}$ & $\mathbf{3 0}$ & $\mathbf{3 1}$ & $\mathbf{3 2}$ \\
\hline Max small sedan & -8.64 & -4.45 & -9.40 & -11.40 & -8.90 & -13.29 & -23.14 & -23.93 \\
\hline Min small sedan & -0.90 & -0.83 & -0.97 & -5.76 & -0.70 & -0.71 & -0.81 & -0.88 \\
\hline Max Large sedan & -1.48 & -2.17 & -2.67 & -1.48 & -4.04 & -4.08 & -3.42 & -1.10 \\
\hline Min Large sedan & -0.56 & -1.04 & -0.75 & -0.56 & -0.84 & -0.51 & -0.47 & -0.42 \\
\hline Max SUVs & -2.10 & -6.85 & -2.27 & -5.99 & -7.11 & -2.55 & -2.86 & -5.40 \\
\hline Min SUVs & -0.48 & -0.70 & -0.61 & -0.46 & -0.47 & -0.47 & -0.47 & -0.44 \\
\hline Max Pickups/vans & -1.35 & -1.42 & -2.04 & -1.73 & -2.35 & -2.36 & -3.48 & -3.57 \\
\hline Min Pickups/vans & -0.63 & -0.65 & -0.76 & -0.59 & -0.62 & -0.61 & -0.53 & -0.56 \\
\hline Max Luxury & -14.92 & -15.10 & -18.75 & -11.34 & -14.14 & -11.34 & -21.22 & -19.11 \\
\hline Min Luxury & -0.54 & -0.56 & -0.54 & -0.54 & -0.53 & -0.61 & -0.63 & -0.60 \\
\hline
\end{tabular}

\section{Calculation of Own Price Elasticities}

The own price elasticities were calculated from the coefficient equations. Since elasticity, by definition, is the percentage change in quantity divided by the percentage change in price and $\frac{\partial P_{x}}{\partial Q_{x}}$ shows the change in price for a $\partial Q_{x}$

one unit change in quantity, quantity is changing by one unit. Therefore, the proportional change in quantity is the change in quantity divided by the total quantity: (1/total sales in segment). 
The percentage change in price is calculated as the change in price divided by the current price. Since $\frac{\partial P_{x}}{\partial Q_{x}}$ represents the change in price, own price elasticity is therefore:

$$
\frac{\partial P}{\partial Q} \cdot \frac{Q}{\text { price }}
$$

Specifically, with an inverse demand function the calculation is:

$$
\frac{\left(\frac{1}{\text { total sales in segment }}\right)}{\left(\frac{\text { coefficien t of demand representi ng the change in price caused by the change in quantity in segment }}{\text { price in segment }}\right)}
$$

\section{Results of the Revealed Demand System}

Applying these formulas to the results of the minimum/maximum coefficients yielded the elasticities for the last unit sold in each segment for each quarter. These results are shown in Table 1. The results indicate the median elasticities for the 32 quarters between 1989 and 1996 are between -1.18 to -4.71 for small vehicles, -0.65 to -2.94 for large vehicles, -0.52 to -2.55 for sport utility vehicles, -0.72 to -4.89 for pickups and -0.54 to -15.10 for luxury vehicles. These elasticities are summarized in Table 2.

\section{Model Failure in Quarter 2}

The model was unable to find a solution for the second quarter. This could be a result of problems in the data or incorrectly assuming Cournot-Nash behavior in the model. Problems in the data may include inaccurately reported sales or price information. Incorrectly assuming Cournot-Nash behavior when firms behave in a different manner would result in firms not satisfying the first order conditions used in this paper's model. For example, if firms take into consideration how other firms will react to output changes, this will change each firm's first order condition.

Another way firms might not act in the Cournot-Nash framework is the possibility that at least one firm was not short run profit maximizing. Firms may not profit maximize in the short run to gain market share or exposure. This latter situation might be present in the second quarter of 1989. In this quarter, Chrysler achieved the highest market share of the 32 quarters in the lucrative SUV market with a 30 percent share. Also in this quarter, the alternative producers, mostly Japanese producers were held to a 14 percent share, their lowest market share in this segment during the 32 quarters examined. In the following quarters, Chrysler and the alternative producers returned to their historical averages of 25 percent and 18 percent respectively. It is possible that Chrysler, the smallest of the surviving domestic auto producers, tried some strategic action because it felt particularly vulnerable to the influx of Japanese manufacturing capacity in the U.S. that was occurring during this period. During the 1989 to 1990 period, the Japanese added almost 200,000 units of capacity in the sport utility segment (Harbour Report). This explanation seems consistent with Cournot-Nash behavior observed in other markets. According to this explanation, Chrysler was unable or unwilling to maintain its sub-optimal level of output, and relented back to its lower market share. 
Table 2: Min/Max Own Price Elasticities by Segment

\begin{tabular}{|c|c|}
\hline Segment & Median Elasticities \\
\hline Small & -1.18 to -4.71 \\
\hline Large & -0.65 to -2.94 \\
\hline SUV & -0.52 to -2.55 \\
\hline Pickup & -0.72 to -4.89 \\
\hline Luxury & -0.54 to -15.10 \\
\hline
\end{tabular}

Table 3: Own Price Elasticity Results Compared to Prior Research

\begin{tabular}{|c|c|c|}
\hline Author & Segment & Elasticity range \\
\hline Cecchinini & European market & -2.63 to -4.56 \\
\hline BLP & small & -5.66 to -6.43 \\
\hline Goldberg & small & -3.29 to -6.22 \\
\hline Culp* & small & $-\mathbf{1 . 1 8}$ to $-\mathbf{4 . 7 1}$ \\
\hline Goldberg & luxury & -1.91 to -3.13 \\
\hline Culp* & luxury & $-\mathbf{0 . 5 3}$ to $-\mathbf{1 5 . 1 0}$ \\
\hline Culp* & Large & $\mathbf{- 0 . 6 5}$ to $\mathbf{- 2 . 9 4}$ \\
\hline Goldberg & pickups & -2.69 to -5.50 \\
\hline Culp* & pickups & $\mathbf{- 0 . 7 3}$ to $-\mathbf{4 . 8 9}$ \\
\hline Culp* & SUV & $\mathbf{- 0 . 5 2}$ to $\mathbf{- 2 . 5 5}$ \\
\hline Various authors prior to 1972 & all & -0.6 to -1.2 \\
\hline Hess & all & -0.26 to -1.63 \\
\hline Median results. & \\
\hline
\end{tabular}

* Median results. Results in some quarters may have wider or narrower ranges.

\section{Comparison of Elasticity Results to Other Research}

The results in Table 3 show that the elasticities estimated by statistical methods are similar to those generated by this paper's mathematical approach. While the results are compiled into one table for comparison, the results are not strictly comparable because the ranges have different interpretations.

Statistical studies generate results that report values of variables that generate the "best fit" to match observed data. The reported value of the variables may differ from the true value because of random error. The true value of the variable may be either slightly higher or slightly lower than the value estimated. Therefore, statisticians create a range of values that are likely to contain the true value with certain probability, usually 80,90 , or 95 percent. This range is called a confidence interval and the further away a value is from the mean, the less likely it is the true value of the estimated variable. The ranges reported in Table 3 from other researchers are confidence intervals, while the ranges reported in Table 3 from this researcher are not confidence intervals. Instead, they indicate the minimum/maximum values of elasticity found that still satisfy the system of first order conditions established in the mathematical model.

In theory, the true value of elasticity is just as likely to occur at the extremes of the ranges for a mathematical model as values toward the center of each range. In this model, however, the true values are unlikely to occur at the extremes because constrained optimization results for maximum and minimum are known to occur at the boundaries of their constraints and the nature of the constraints used in the model. In this model, the binding constraints were on the marginal cost of each vehicle. In particular, marginal cost of each vehicle was not to exceed vehicle price and was to be greater than a significantly low estimate of marginal cost. Since these marginal cost constraints have a wider range than is likely to occur, the constrained maximum/minimum optimization results based on these constraints are also likely to have a wider range than is likely to occur. Therefore, it is less likely that the values at the extremes would be the true values. The range of values could be reduced by tightening the restrictions placed on each firm's cost and profit margin per vehicle, but such changes would require more accurate information than was available to this researcher. 
Another important difference between interpreting a statistical model's results and this mathematical approach is the interconnectivity of the elasticities estimates from one segment to the next. The interconnectivity means the elasticity in one vehicle segment affects the elasticity results in the remaining segments. Just as if a person has 10 hours of free time to spend on either fishing or working and the person decides to work 6 hours, mathematically this person is restricted to spending no more than 4 hours fishing. In the model developed in this paper, there is a system of first order conditions and each first order condition must be satisfied. If, for example, the value of elasticity for SUVs is thought to be very elastic, say 2.0., this might force the remaining vehicle segment's elasticities to be rather inelastic in order to satisfy the first order conditions. That is, the value taken by one variable will limit the range of values taken by other variables in the system. While the ranges may seem very large taken individually, the system as a whole is more restrictive. This result might be useful to a researcher who wishes to examine the impact on the entire automobile market rather than one segment. For example, if a researcher wished to examine the impact of a tax placed on SUVs on automakers' profits, the researcher would not just want to know the impact of the tax on SUV sales but on total vehicle sales taking into account substitution away from SUVs by consumers.

\section{Conclusions and Areas for Future Research}

The model developed in this paper succeeded in estimated price elasticities of vehicle demand using solely a mathematical approach and without specifying a particular function form for utility. While this paper assumed homogenous segments and placed restrictions on market structure and firm behavior, significantly, the estimates of vehicle elasticity generated by this method are comparable to the results generated by the various statistical approaches of other researchers.

The model developed also has the advantage that the elasticity results in each segment are interconnected. The interconnectivity of elasticities restricts the possible values for the entire system of elasticity estimates in the automotive market. Therefore, the approach developed in this paper could be attractive to researchers predicting the impact on the entire automotive market of changes in taxes or production costs in one or many segments. In addition, unlike the prior methods of estimating demand in the automotive industry, the researcher would not have to place restrictions on consumer substitution patterns to obtain elasticity estimates.

Another important aspect of this paper is the use of a global optimization program to find ranges of values that satisfy a model that could not have been solved explicitly. Future researchers could find this technique useful whenever the true nature of a model cannot be perfectly described.

The next advance for this type of mathematical model would be to allow for differentiation among products within the same segment. Expanding the model in this way would increase the complexity of the model exponentially and require significant processing power. However, as optimization programs become more efficient and computers faster, this may not be a limitation.

\section{References}

1. Arguea, Nestor, Cheng Hsiao, G.A. Taylor (1994): "Estimating Consumer Preferences Using Market Data-An Application to US Automobile Demand," Journal of Applied Econometrics, 9, 1-18.

2. Arguea, Nestor and Cheng Hsiao (1993): "Econometric Issues of Estimating Hedonic Price Functions: With an Application to the U.S. Market for Automobiles," Journal of Econometrics, 56, 243-267.

3. Bajic, Vladimir (1993): "Automobiles and Implicit Markets: An Estimate of a Structural Demand Model for Automobile Characteristics," Applied Economics, 25, 541-551.

4. Bajic, Vladimir (1988): "Market Shares and Price-Quality Relationships: An Econometric Investigation of the U.S. Automobile Market," Southern Economic Journal, 54, 888-900.

5. Berndt, Ernest R., Ann F. Friedlaender, Judy Shaw-Er-Wang Chaing (1991): "Interdependent Pricing and Markup Behavior: An Empirical Analysis of GM, Ford and Chrysler," MIT Press, 55. 
6. Berry, Steven, James Levinsohn, Ariel Pakes (1995): "Automobile Prices in Market Equilibrium," Econometrica, 63, 841-890.

7. Cecchini, Laurence (2000): "Differenciation du produit et concurrence," Revue Economique, 51, 103-117.

8. Consumer Expenditure Survey, Bureau of Labor Statistics (1989-1996).

9. Fairen, Victor (1996): "A Replicator Theory Model of Competition through Imitation in the Automobile Market," Journal of Economic Behavior and Organization, 29, 141-57.

10. Fershtman, Chaim, Neil Gandal, Sarit Markovich (1999): "Estimating the Effect of Tax Reform in Differentiated Product Oligopolistic Markets," Journal of Public Economics, 74, 151-70.

11. Friedlaender, Ann F., Clifford Winston, Kung Wang (1983): "Costs, Technology, and Productivity in the U.S. Automobile Industry," Bell Journal of Economics, 14, 1-20.

12. Goldberg, P.K. (1995): "Product Differentiation and Oligopoly in International Markets: The Case of the U.S. Automobile Industry," Econometrica, 63, 891-951.

13. Greene, William H. (2000): Econometric Analysis: Fourth Edition, Prentice-Hall.

14. Harbour Yearbook (1979-1996).

15. Hess, Alan (1977): "A Comparison of Automobile Demand Equations," Econometrica, 45, 683-701.

16. Langlois, Catherine C. (1996): "Do Japanese Automakers Maximize Profits? A Systems Analysis of the Pricing of Automobile Inventories," American Economist, 40, 65-76.

17. Langlois, Catherine (1989): "Markup Pricing Versus Marginalism: A Controversy Revisited", Journal of Post Keynesian Economics, 12, 127-51.

18. Levinsohn, James (1988): "Empirics of Taxes on Differentiated Products: The Case of Tariffs in the U.S. Automobile Industry," Trade Policy Issues \& Empirical Analysis, National Bureau of Economic Research Conference Report Series Chicago and London, University of Chicago Press.

19. Office of Automotive Transportation.

20. Ward's Automotive. 